\title{
Paracoccidioidomycosis manifested by sarcoidosis-like cutaneous lesions and caused by Paracoccidioides brasiliensis sensu stricto (S1a)*
}

\author{
Sílvio Alencar Marques ${ }^{1}$, Marilia Formentini Scotton Jorge ${ }^{2}$, Marluce Francisca Hrycyk³, \\ Sandra de Moraes Gimenes Bosco ${ }^{4}$
}

DOI: http://dx.doi.org/10.1590/abd1806-4841.20188293

\begin{abstract}
Molecular studies have shown more than one species of the genus Paracoccidioides to be the causal agent of paracoccidioidomycosis. Efforts have been made to correlate the identified species with epidemiological and clinical data of patients, aiming to determine the real meaning and impact of new species. Bearing this objective in mind, the authors report a clinical case of paracoccidioidomycosis, from São Paulo state, Brazil, that manifested as uncommon sarcoid-like cutaneous lesions and was caused by Paracoccidioides brasiliensis sensu stricto (S1a). The patient was treated with itraconazole $200 \mathrm{mg} /$ day for 12 months, with complete clinical remission.
\end{abstract}

Keywords: Paracoccidioidomycosis; Sarcoidosis; Skin diseases; Skin manifestations

Paracoccidioidomycosis (PCM) is a systemic mycosis caused by thermally dimorphic fungi of the genus Paracoccidioides. Recently, molecular studies have shown that $P$. brasiliensis (S1a, S1b) and related species $P$. americana (S2), P. restrepiensis (S3), P. venezuelensis (S4) and P. lutzii are possible etiological agents. ${ }^{1}$ Airborne infections occur mainly in rural areas, and the primary complex develops in the lungs. ${ }^{2}$ Clinical manifestation in adult patients typically includes oral, cutaneous and pulmonary involvement. Cutaneous lesions are reported to occur in $30 \%$ to $61.2 \%$ of studied patients. ${ }^{3}$ Most frequently, skin lesions result from hematogenous spread of fungi. The most common forms of lesion are ulcerative and ulcer- ous-vegetative, reported in up to $42.8 \%$ of cases in one series. ${ }^{3}$ Conversely, an infiltrative pattern similar to the plaque-type lesion of cutaneous sarcoidosis is very uncommon. ${ }^{4}$ The authors report a male patient with an unusual and extensive cutaneous involvement of a sarcoid-like skin lesion caused by P. brasiliensis sensu stricto (S1a). ${ }^{5}$

A 53-year-old male patient, from a rural area in the municipality of São Manuel (SP), was referred for evaluation of a facial skin lesion that had evolved over one year. Fever, weight loss, pulmonary complaints and comorbidities were denied, as was alcohol and tobacco use. On examination, we observed an infiltrative sarcoid-like skin lesion on the face (Figures 1 and 2). With the hy-

\footnotetext{
Received 14 March 2018.

Accepted 06 April 2018.

* Work conducted at the Department of Dermatology and Radiotherapy, Faculdade de Medicina de Botucatu, Universidade Estadual Paulista, Botucatu (SP), Brazil.

Financial support: None.

Conflict of interest: None.

Department of Dermatology and Radiotherapy, Faculdade de Medicina de Botucatu, Universidade Estadual Paulista, Botucatu (SP), Brazil.

Dermatology Service, Hospital das Clínicas, Faculdade de Medicina de Botucatu, Universidade Estadual Paulista, Botucatu (SP), Brazil.

Laboratory of Microbiology and Immunology, Faculdade de Ciências Biológicas e Agrárias, Universidade do Estado de Mato Grosso, Alta Floresta (MT), Brazil.

4 Laboratory of Medical Mycology, Departamento de Microbiologia e Imunologia, Instituto de Biociências de Botucatu, Universidade Estadual Paulista, Botucatu (SP), Brazil.
}

MAILING AdDRESS:

Sílvio Alencar Marques

E-mail: smarques@fmb.unesp.br 


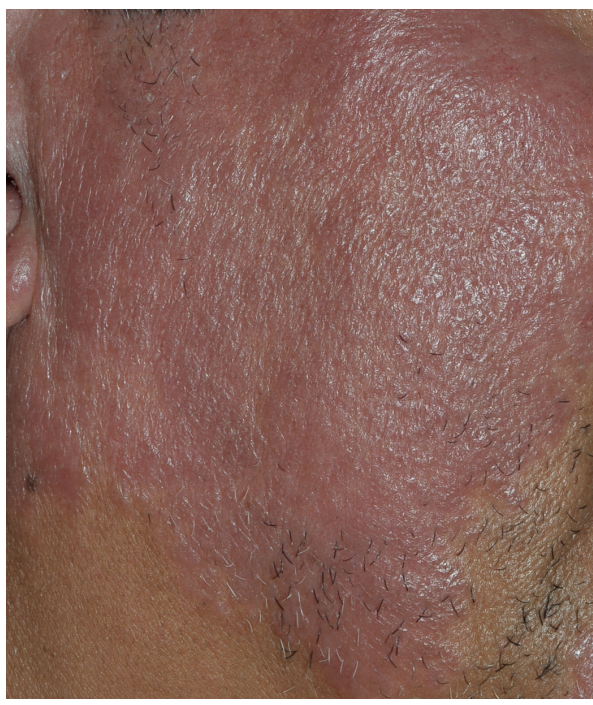

Figure 1:

Paracoccidioidomycosis: erythematoviolaceous, infiltrated, sarcoidosis-like lesions on the face

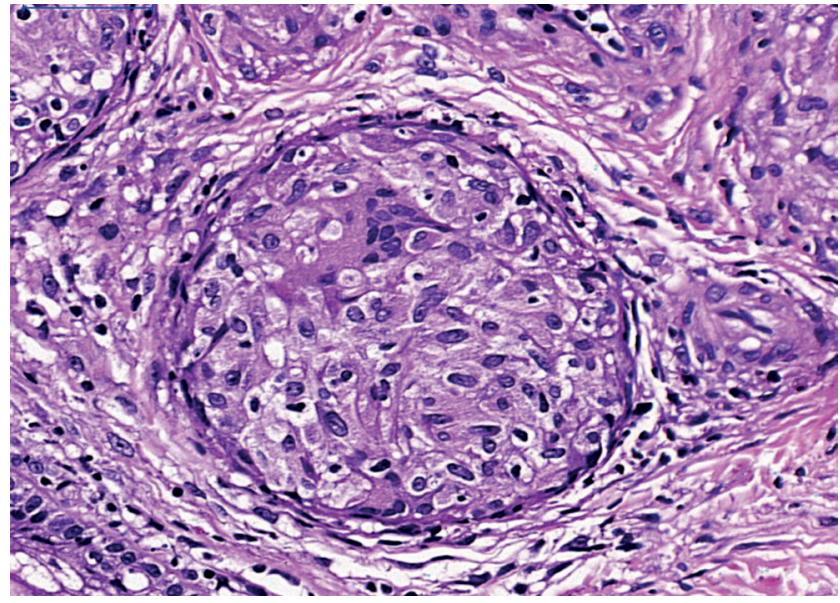

Figure 3: Paracoccidioidomycosis: well-formed epithelioid granuloma with giant cell and no visible fungus. Hematoxylin \& eosin, x100

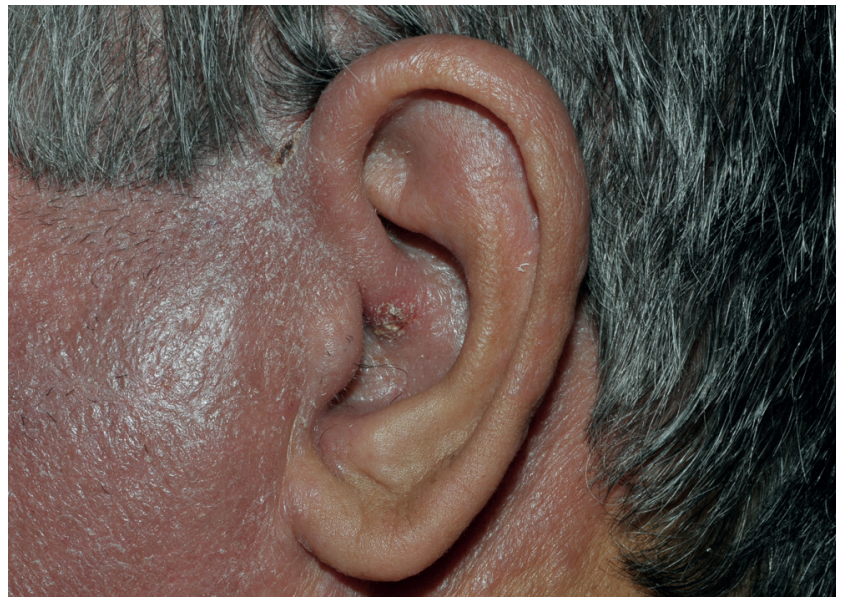

Figure 2: Paracoccidioidomycosis: detail of infiltrated lesion and shallow ulcer

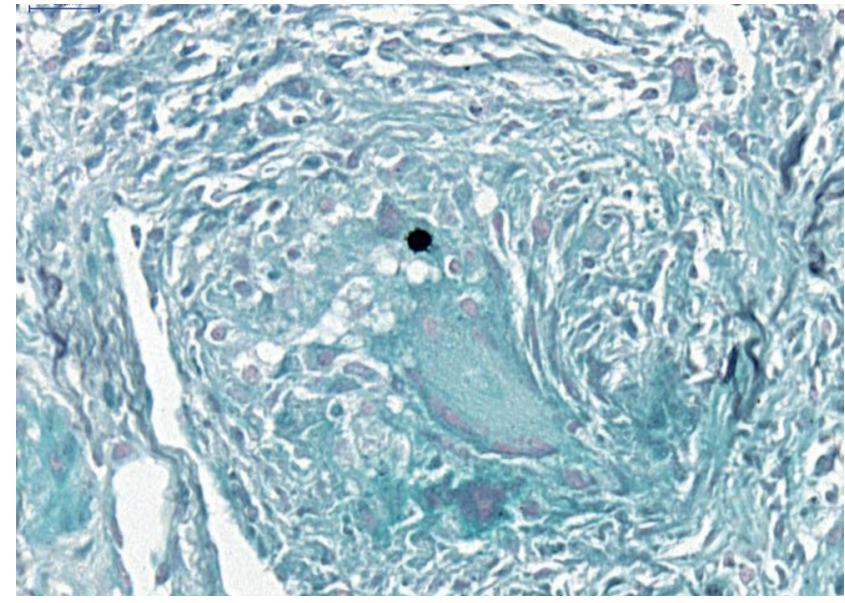

FIGURE 4: Paracoccidioidomycosis: isolated fungus cell with discrete multiple sporulation amid epithelioid granuloma. Grocott-Gomori, x100

In PCM, sarcoid-like lesion is an expression of equilibrium pothesis of B-cell lymphoma or PCM, the lesion was submitted to a punch biopsy. The histopathology revealed a dense, granulomatous inflammatory dermal infiltrate of histiocytes and multinucleated giant cells with rare fungal cells, viewed in greater specificity with silver staining (Figures 3 and 4). Culture from a biopsy fragment incubated on Mycose $^{\circledR}$ at $35^{\circ} \mathrm{C}$ showed yeast cells diagnostic of Paracoccidioides genus. The isolate was molecularly characterized as P. brasiliensis sensu stricto (S1a) by sequencing ITS rDNA and gp43 exon 2 loci. ${ }^{5}$ PCR-RFLP (Restriction Fragment Length Polymorphism) of $t u b 1$ gene was also carried out to enable differentiation among Paracoccidioides spp. ${ }^{5,6}$ A thin-slice computed tomography of the thorax and abdomen showed no abnormalities. Laboratory data were within normal limits, with exception of ESR of $20 \mathrm{~mm} / \mathrm{h}$. Antibody screens for HIV, HBV, HCV and Paracoccidioides spp. (IDD) tested negative. Itraconazole $200 \mathrm{mg}$ / day was used for 12 months, with complete clinical remission. 


\section{REFERENCES}

1. Turissini DA, Gomez OM, Teixeira MM, McEwen JG, Matute DR. Species boundaries in the human pathogen Paracoccidioides. Fungal Genet Biol. 2017;106:9-25

2. Marques SA. Paracoccidioidomycosis: epidemiological, clinical, diagnostic and treatment up dating. An Bras Dermatol. 2013;88:700-11.

3. Marques SA, Cortez DB, Lastoria JC, Camargo RMP, Marques MEA. Paracoccidioidomycosis: frequency, morphology, and pathogenesis of tegumentary lesions. An Bras Dermatol. 2007;82:411- 7 .

4. Abreu MAMM, Lastória JC, Mattos ALA, Alchorne MMA. Paracoccidioiodomycosis with sarcoid-like lesions: a diagnostic challenge. Rev Soc Bras Med Trop. 2017;50:273-6.

5. Hrycyk MF, Garcia Garces H, Bosco SMG, de Oliveira SL, Marques SA, Bagagli E. Ecology of Paracoccidioides brasiliensis, P. lutzii and related species: infection in armadillos, soil occurrence and mycological aspects. Med Mycol. 2018; Epub ahead of print.
6. Roberto TN, Rodrigues AM, Hahn RC, de Camargo ZP. Identifying Paracoccidioides phylogenetic species by PCR-RFLP of the alpha-tubulin gene. Med Mycol. 2016;54:240-7.

7. Marques SA, Lastória JC, Putinatti MSMA, Camargo RMP, Marques MEA. Paracoccidioidomycosis: infiltrated, sarcoid-like cutaneous lesions misinterpreted as tuberculoid leprosy. Rev Inst Med Trop São Paulo. 2008;50:47-50.

8. Shikanai-Yasuda MA, Mendes RP, Colombo AL, Queiroz-Telles F, Kono ASG, Paniago AMM, et al. Brazilian guidelines for the clinical management of paracoccidioiodomycosis. Rev Soc Bras Med Trop. 2017;50:715-40.

9. Munõz JF, Farrer RA, Desjardins CA, Gallo JE, Sykes S, Sakthikumar S, et al. Genome Diversity, Recombination, and Virulence across the Major Lineages of Paracoccidioides. mSphere. 2016;1. pii: e00213-16.

Approval of the final version of the manuscript, Conception and planning of the study, Elaboration and writing of the manuscript, Critical review of the literature, Critical review of the manuscript
Marilia Formentini Scotton Jorge
iD ORCID 0000-0003-1667-5160

Intellectual participation in propaedeutic and/or therapeutic conduct of the cases studied, Critical review of the literature, Critical review of the manuscript Marluce Francisca Hrycyk $\quad$ (iD) ORCID 0000-0003-3485-6897

Approval of the final version of the manuscript, Obtaining, analyzing and interpreting the data

Sandra de Moraes Gimenes Bosco $\quad$ (iD) ORCID 0000-0002-6363-3740

Obtaining, analyzing and interpreting the data, Critical review of the literature, Critical review of the manuscript

How to cite this article: Marques SA, Jorge MFS, Hrycyk MF, Bosco SMG. Paracoccidioidomycosis manifested by sarcoidosis-like cutaneous lesions and caused by Paracoccidioides brasiliensis sensu stricto (S1a). An Bras Dermatol. 2018;93(6):902-4. 